\title{
The gender health gap in Europe's ageing societies: universal findings across countries and age groups?
}

\author{
Alina Schmitz ${ }^{1} \cdot$ Patrick Lazarevič ${ }^{2}$ (i)
}

Published online: 17 February 2020

(c) The Author(s) 2020

\begin{abstract}
We provide a systematic country and age group comparison of the gender gap in several generic health indicators and more specific morbidity outcomes. Using data from the Survey of Health, Ageing and Retirement (SHARE), we examined the gender gap in the prevalence of poor self-rated health, chronic health conditions, activity limitations, multimorbidity, pain, heart attacks, diabetes, and depression in three age groups (50-64,65-79, and 80+) based on linear probability models with and without adjustment for covariates. While women were typically disadvantaged regarding poor self-rated health, chronic health conditions, activity limitations, multimorbidity, pain, and depression, men had a higher prevalence of heart attacks and diabetes. However, the gender gap's magnitude and sometimes even its direction varied considerably with some age trends apparent. Regarding some health indicators, the gender gap tended to be higher in Southern and Eastern Europe than in Western and Northern Europe. All in all, the presence of a gender health gap cannot be regarded as a universal finding as the gap tended to widen, narrow or even reverse with age depending on the indicator and country.
\end{abstract}

Keywords Health inequalities · Age differences · Cross-country comparison · Survey of Health, Ageing and Retirement in Europe (SHARE)

\section{Introduction}

Because of rapid population ageing in Europe, there is an increasing interest in the health status of people at older ages and differences in the health status of women and men have attracted scholarly attention for a long time. Empirical results on gender inequalities in health may appear puzzling as the direction of the gender health gap depends on the indicator. The prevalence of potentially lethal diseases, like coronary heart diseases, stroke, or lung cancer, is higher in men (Read and Gorman 2011; Oksuzyan et al. 2018).

Responsible editor: Susanne Iwarsson.

Patrick Lazarevič

Patrick.Lazarevic@oeaw.ac.at

Alina Schmitz

alina.schmitz@tu-dortmund.de

1 TU Dortmund, Emil-Figge-Str. 50, 44227 Dortmund, Germany

2 Austrian Academy of Sciences, Vienna Institute of Demography, Vordere Zollamtsstraße 3, 1030 Vienna, Austria
Accordingly, women outlive men for several years in all countries of the European Union (European Commission 2015). In contrast, more women report non-fatal but debilitating conditions, such as arthritis, depression, and cognitive impairment (Crimmins et al. 2010; Leveille et al. 2000; Schmitz and Brandt 2019). For self-rated health (SRH), results are less uniform, but many studies report a female disadvantage which is attenuated or even reversed when other health indicators are controlled for (Crimmins et al. 2010; Bardage et al. 2005).

While some scholars draw conclusions like 'women are sicker, but men die quicker' - the so-called male-female health survival paradox (Oksuzyan et al. 2008)—-these 'taken-for-granted assumptions' have been criticised by others (Lahelma et al. 2001) as the magnitude of the gender health gap differs remarkably depending on the health indicator and country under study. For the age group 50+, Crimmins et al. (2010) examined gender differences in functional limitations, disability, disease prevalence, and SRH. They conclude that even though there is a remarkable consistency in the direction of gender differences, their magnitude shows enormous variation between countries. This holds true for indicators like SRH and depression along with more 
objective indicators, such as activity limitations and chronic diseases like arthritis. Recent studies confirmed this regional variation of the magnitude of the gender gap in frailty and activities of daily living in the older population (Ahrenfeldt et al. 2019; Scheel-Hincke et al. 2019). Furthermore, there are significant health differences between age groups and birth cohorts (Lahelma et al. 2001; Bird et al. 2012; Macintyre et al. 1996). Thus, differences in women's and men's morbidity profiles are neither a universal finding across age groups and health indicators nor the magnitude of the gender health gap invariant across countries and birth cohorts (Bird et al. 2012).

\section{(Social) Explanations for gender inequalities in health}

There are mainly three explanatory approaches for gender differences in health: biological, methodological, and social explanations. While biological explanations focus on the role of sex hormones and other differences in physiological systems, methodological explanations assume that women are more likely to seek medical advice, report health problems in interview situations, and report differentially when seeking help (Acciai and Hardy 2017). Studies that empirically test such claims are scarce and the few existing studies focusing on well-being and depression provided no evidence supporting this hypothesis (Acciai and Hardy 2017; Oksuzyan et al. 2019). Furthermore, gender stereotypes might influence the practice of medical diagnosis and the expression of symptoms by women and men (Sen et al. 2002). It has also been argued that men tend to use health services less frequently than women, possibly resulting in an underdiagnosis of certain diseases. However, it has been shown that gender differences in doctor consultations are attenuated or even reversed when overall health or the severity of health conditions is considered (Roy and Chaudhuri 2012; Courtenay 2000).

Social explanations highlight the importance of social determinants of health-i.e. the conditions in which people are born, grow, live, work, and age. One key social determinant of health is gender, that is, "the socially constructed roles, behaviour, activities, and attributes that a particular society considers appropriate for men and women' (WHO 2019). Gender roles affect the way women and men engage in education, the labour market, domestic and care work, and health behaviours (Loretto and Vickerstaff 2015; Courtenay 2000; Haberkern et al. 2015). Additionally, they affect the design of formal institutions and policies, constraining or incentivising individuals' choices throughout the life course (Bonsang et al. 2017; Bird and Rieker 2008). Social explanations for gender inequalities in health stress the relevance of health behaviours, such as tobacco and alcohol consumption, dietary habits, physical activity, and healthcare utilisation (Oksuzyan et al. 2010; Mahalik et al. 2007; Luy 2003), socio-economic factors, such as financial resources and working conditions (Read and Gorman 2011), and psychosocial factors, such as critical life events, social network characteristics, and coping styles (Thoits 2011; Lachman et al. 2011). From this point of view, gender differences in health arise from a gendered access to protective resources (e.g. education, income, and social support) and a differential exposure to health risks (e.g. occupational hazards, family responsibilities like caring for older relatives, and unhealthy behaviours).

Recent studies have revealed considerable differences between European societies regarding gendered patterns of family responsibilities (Schmid et al. 2012; Brandt 2013) and labour market participation (Cipollone et al. 2012; Edge et al. 2017) so that country differences in the gender health gap come with little surprise. Further, gender differences in health promoting resources and health risks do not only vary depending on the country context, but are also likely to differ between age groups and people of different birth cohorts. Thus, separate analyses by age groups are necessary-also because aggregated data over all age groups would bias results towards younger ages due to their typically greater number of cases. Still, most studies on gender differences in health do not differentiate between age groups so that between-age-group variation remains hidden. Our study provides an analysis of the gender health gap in old age for several generic health indicators and more specific morbidity outcomes. We compare the health status of women and men between 16 European countries stratified by age both unadjusted and adjusted for relevant socio-demographic characteristics.

\section{Data and methods}

\section{Study population and sample}

Data were drawn from the sixth wave of the Survey of Health, Ageing and Retirement in Europe (SHARE), a cross-country comparable and nationally representative study on health and social conditions of persons aged 50 years and older living in private households. A detailed description of the survey methodology has been provided elsewhere (Börsch-Supan et al. 2013; Munich Center for the Economics of Aging 2018). We grouped the sample into three age groups $(50-64,65-79$, and $80+)$. Our analysis covers 16 countries, including Northern Europe (Denkmark and Sweden), Eastern Europe (Croatia, Czech Republic, Estonia, Poland, and Slovenia), Southern Europe (Greece, Italy, and Spain), and Western Europe (Austria, Belgium, France, Germany, Luxembourg, and 
Switzerland). We excluded Portugal from our analyses due to small sample sizes in older age groups. In total, 8252 respondents were excluded due to missing values for at least one of the variables of interest. The final sample included 55,446 participants.

The sample's mean age amounted to 65.5 years (Table A1 in the Appendix). Around $51 \%$ of the samples belonged to the age group 50-64, these aged 65-79 comprised another third (37\%), and around $12 \%$ of the study participants are aged $80+$. This highlights the necessity for age stratification to unveil potential age-specific differences since the weight of the respondents aged 50-64 in the sample would mask any differences in older age groups. When comparing age groups, the share of women increased with age in every country and amounted to around 63 per cent in the age group $80+$ in the overall sample-probably due to men's lower life expectancy.

\section{Variables}

To present a broad overview of health differences, this study uses a diverse set of health indicators, namely SRH, chronic health conditions, the global activity limitation indicator (GALI), multimorbidity, the presence of pain, and the prevalence of heart attacks, diabetes, and depression. To compare the results between health indicators, we dichotomised all variables.

\section{Self-rated health}

SRH represents a subjective overall evaluation of a person's health status which is highly correlated with several other health indicators and predicts future morbidity, functional limitations, and mortality (Jylhä 2009). SRH was assessed by asking 'Would you say your health is...excellent/very good/good/fair/poor?'. A binary variable was coded into 'good health' (good or better) versus 'poor health' (fair or poor).

\section{Chronic health conditions}

Respondents were asked a global chronic morbidity question: 'Some people suffer from chronic or long-term health problems. By chronic or long-term we mean it has troubled you over a period of time or is likely to affect you over a period of time. Do you have any such health problems, illness, disability, or infirmity?' This indicator is, like SRH, part of the 'Minimum European Health Module' (MEHM) that is used in multiple administrative surveys to shortly assess the respondent's health status (Robine and Jagger
2003) and is further used to calculate healthy life expectancy (Jagger et al. 2008).

\section{Global activity limitation indicator}

GALI is a comprehensive indicator that has proved to appropriately reflect health-based activity limitations in cross-country comparisons (van Oyen et al. 2006; Jagger et al. 2010). It was collected by the question: 'For the past 6 months at least, to what extent have you been limited because of a health problem in activities people usually do?' (not limited/limited but not severely/severely limited). We dichotomised the variable into 'no limitations' versus 'limitations'.

\section{Multimorbidity}

Multimorbidity, the presence of several diseases, is a common health condition in old age and associated with an elevated risk of mortality, functional limitations, and reduced quality of life (Marengoni et al. 2011). In accordance with other studies (see the systematic review by Violan et al. (2014), we defined multimorbidity as reporting diagnoses of at least two diseases or chronic health conditions (heart attack or any other heart problem; high blood pressure or hypertension; high blood cholesterol, stroke or cerebral vascular disease; diabetes or high blood sugar; chronic lung disease; cancer; stomach/duodenal ulcer; Parkinson disease; cataracts; hip fracture or other fractures; dementia, organic brain syndrome or any other serious memory impairment; other affective or emotional disorders; rheumatoid arthritis, osteoarthritis, other rheumatism; chronic kidney disease).

\section{Presence of pain}

Chronic pain is a highly salient health condition with immense psychosocial consequences as it impairs a person's well-being and the ability to maintain an independent lifestyle (Breivik et al. 2006). According to the question 'Are you troubled with pain?', we grouped the respondents in those reporting or not reporting the presence of pain.

\section{Chronic diseases}

Additionally to multimorbidity, we analysed several chronic diseases which are among the leading causes for disability worldwide (Murray and Lopez 2013). These were diagnosed heart attacks (including myocardial infarction, coronary thrombosis, or any other heart condition including congestive heart failure; shortened to 'heart attacks' below), diagnosed diabetes or high blood sugar (shortened to 'diabetes'), and a high probability of depression according to the EUROD scale, consisting of twelve items on depressive symptoms. 
In accordance with other studies, we chose a cut-off point of four symptoms to identify respondents with a high risk of depression (Prince et al. 1999).

\section{Covariates}

To account for some of the social determinants of health, we adjusted the estimated gender gaps for several covariates: educational attainment according to the International Standard Classification of Education (UNESCO 1997) with seven categories, marital status (married/registered partnership, divorced/living separated from spouse, never married, widowed), whether their household was able to make ends meet (four categories) or would be able to afford an unexpected expense without borrowing money (yes/no) as assessed by the household head, rural (small town/rural area/village) versus urban (big city, suburbs/outskirts of a big city, or large town) residential area, and the number of doctor's visits during the last year $(0-1 / 2-3 / 4-9 / 10+)$. To account for potentially nonlinear relationships between these variables and the probability of a health condition and due to the variables' scaling, we used all covariates' categories as sets of dummy variables.

\section{Statistical analysis}

We computed country-specific gender gaps via linear probability models (LPM) separately for respondents in the age groups 50-64 years, 65-79 years, and 80+ (i.e. three models per country). Using this approach, the gender coefficients represent the percentage difference in the prevalence of the corresponding health condition by gender in each age group. In a second step, we adjusted these gender gaps for potentially important covariates to account for gender differences in some social determinants of health (i.e. six models per country overall).

In all following analyses, positive estimates represent a higher prevalence of the health problem in women. We weighted all analyses with the calibrated cross-sectional weight provided by SHARE to account for country-specific sampling strategies and national differences in response rates.

\section{Results}

\section{Overall prevalence of health conditions}

Table 1 presents the overall prevalence of the health conditions separately by gender and age. Generally, health conditions were more prevalent in the older age groups. The prevalence of poor SRH, chronic health conditions, activity limitations, multimorbidity, pain, and depression was greater in women in every age group as compared to men. In contrast, heart attacks were more prevalent in men of all age groups as well as diabetes.

\section{The gender health gap by countries and age groups}

In the following graphs, the gender gap is depicted with 95\%-CI separately for the three age groups within each country. For every subgroup, there are two estimates showing the overall gender gap and the gender gap adjusted for covariates.

\section{Poor self-rated health}

As Fig. 1 shows, more women than men reported poor health across most age groups in Southern and Northern Europeat least in the unadjusted models where the gender gaps were greatest in the Southern European countries, but rather small in Northern Europe. In Western and Eastern Europe, the picture was more complex, and the direction of the gender gap within countries partly varied between age groups. Yet, when adjusting for socio-demographic characteristics, the gender gap was rather small in Northern and Southern Europe (with the exception of the oldest age group). In some
Table 1 Prevalence of health conditions in the pooled sample by age (in \%)

\begin{tabular}{|c|c|c|c|c|c|c|c|}
\hline & \multicolumn{3}{|l|}{ Men } & \multicolumn{3}{|c|}{ Women } & \multirow[t]{2}{*}{ Total } \\
\hline & $50-64$ & $65-79$ & $80+$ & $50-64$ & $65-79$ & $80+$ & \\
\hline Poor self-rated health & 29.00 & 39.51 & 56.05 & 28.76 & 45.03 & 66.58 & 38.01 \\
\hline Chronic health conditions & 43.80 & 52.90 & 62.26 & 44.56 & 55.97 & 68.01 & 50.64 \\
\hline Activity limitations & 34.72 & 44.70 & 62.85 & 36.89 & 51.10 & 73.14 & 44.46 \\
\hline Multimorbidity & 32.98 & 53.10 & 62.62 & 35.53 & 59.43 & 72.82 & 46.69 \\
\hline Presence of pain & 36.49 & 39.83 & 47.55 & 45.95 & 56.56 & 67.62 & 46.44 \\
\hline Heart attacks & 8.23 & 16.17 & 24.03 & 3.46 & 10.68 & 18.88 & 10.32 \\
\hline Diabetes & 10.08 & 18.33 & 18.21 & 6.46 & 15.03 & 16.56 & 12.36 \\
\hline Depression & 19.01 & 19.88 & 30.36 & 33.38 & 36.56 & 46.95 & 29.10 \\
\hline
\end{tabular}

Source: SHARE wave 6, release 7.0.0. Author's calculations. All analyses were weighted 
Fig. 1 Gender gap in poor selfrated health across age groups by country. Source: SHARE wave 6 , release 7.0.0. Author's calculations. All analyses were weighted

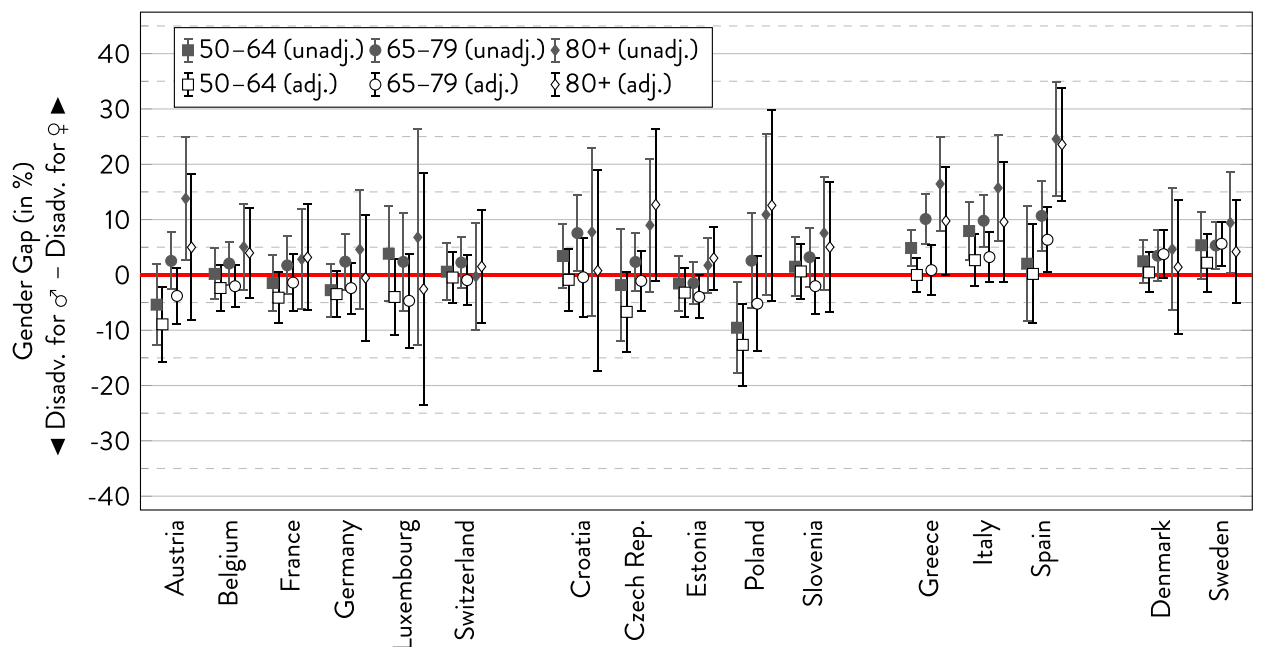

of the Eastern and Western European countries, adjusting for covariates even reversed the gender gap to the disadvantage of men. However, these nominal gaps should be cautiously interpreted, as coefficients were not statistically significant in most cases. Typically, there was an age trend with increasing gender gaps to women's disadvantage, with outstandingly large gender gaps in the oldest age group in Spain.

\section{Chronic health conditions}

For the presence of any chronic health condition, results were similar to the findings for SRH (Fig. 2). While more women reported health conditions in most age groups in Southern and Northern Europe, gender differences were less uniform in Western and Eastern Europe. Except for the older age groups, gender differences were relatively small in all European regions. Outstandingly large gender gaps were, again, observed in the oldest age group in Spain. Where there were rather consistent age trends, the gender gap typically increased to the disadvantage of women, whereas it reversed to the disadvantage of men in France and Switzerland. However, the large confidence intervals highlight the uncertainty of these trends. In other countries, age trends were inconsistent, non-existent, or the gap narrowed at older ages. Adjusting for covariates typically decreased the gender gap or even reversed gender differences to the disadvantage of men.

\section{Activity limitations}

In the unadjusted models, there was a greater prevalence of activity limitations in women than men in most age groups except in Eastern Europe (Fig. 3). In the few cases where the gender gap was at the expense of men, the gap was relatively small and not statistically significant. The gender gap proved particularly pronounced in the oldest age group in Austria and Spain. When comparing age groups, the gender gap increased to the disadvantage of women at older
Fig. 2 Gender gap in chronic health conditions across age groups by country. Source: SHARE wave 6, release 7.0.0. Author's calculations. All analyses were weighted

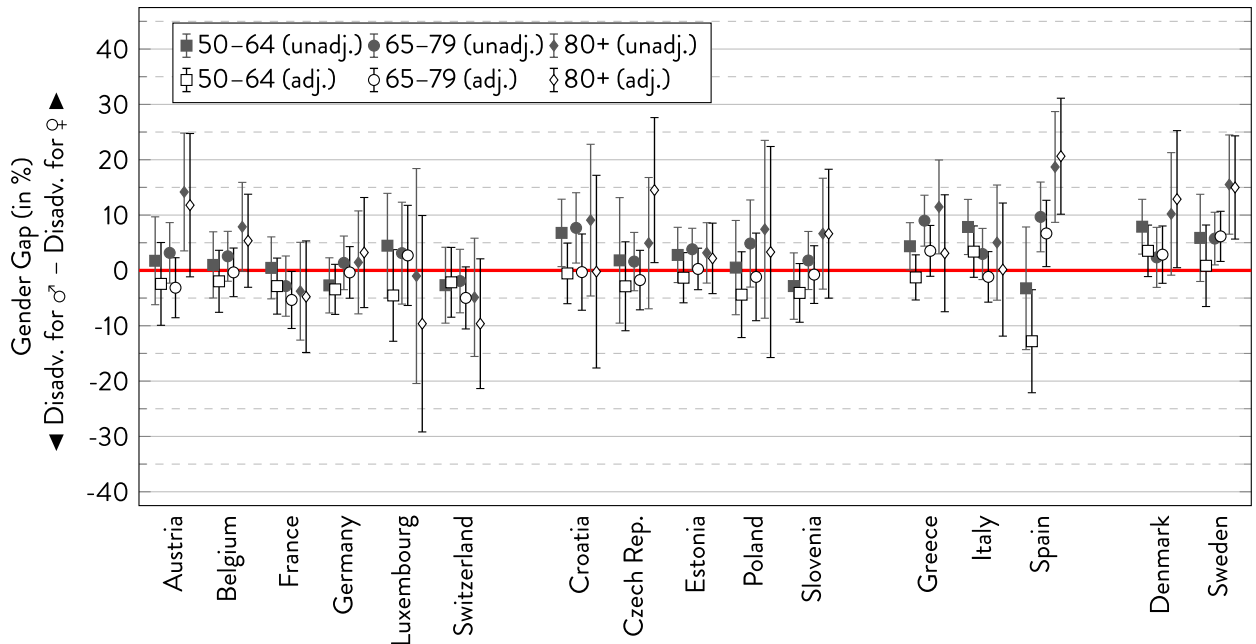


Fig. 3 Gender gap in activity limitations across age groups by country. Source: SHARE wave 6 , release 7.0.0. Author's calculations. All analyses were weighted

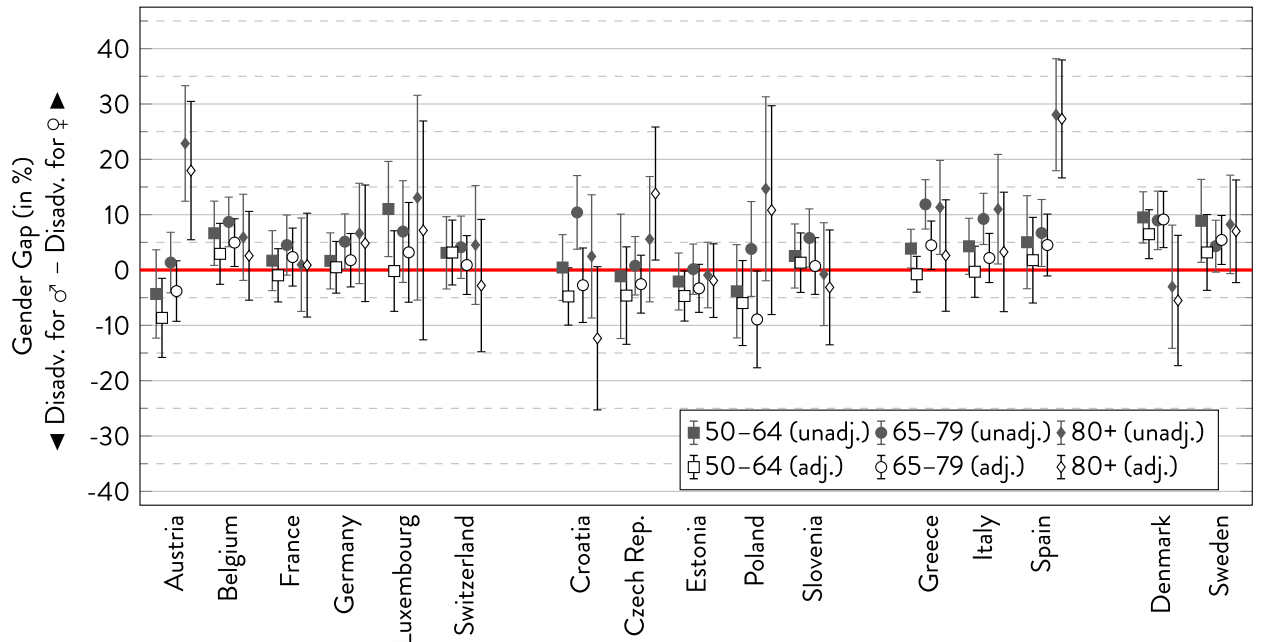

ages in Austria, Germany, the Czech Republic, Poland, and the Southern European countries. Denmark was the only country where it reversed to the disadvantage of men in the oldest age group. In the other countries, there was no clear age trend. Thus, the gender gap in activity limitations overall tended to increase if it changed at all. Regional differences were less pronounced than for SRH and chronic health conditions. Again, controlling for covariates typically reduced the gender gap in most cases and sometimes even reversed it to the disadvantage of men, although not with any statistically significance.

\section{Multimorbidity}

Without adjustment for covariates, there was a (nominally) higher prevalence of multimorbidity in women of most age groups in almost every country (Fig. 4). Outstandingly large gender gaps were observed in the oldest old in Austria and Spain. Notable counterexamples were found in some age groups in Austria, Luxembourg, Switzerland, and Slovenia-showing a (slightly) higher prevalence of multimorbidity in men. However, the gender gaps were statistically insignificant in most countries and age groups. In most countries with rather consistent age trends, the gender gap in multimorbidity was more pronounced at the expense of women in the older age groups (Austria, Germany, Poland, Slovenia, Italy, Spain, and Sweden). In contrast, the gap reversed to the disadvantage of men in Luxembourg. In the remaining countries, age differences were inconsistent. Regarding the countries geographical location, the gender gap tended to be relatively small in Northern Europe. Adjusting for covariates did again not significantly change the results. As before, if there were larger differences between the unadjusted and the adjusted model, they typically reduced the gender gap or even reversed the gender gap to the disadvantage of men.
Fig. 4 Gender gap in multimorbidity across age groups by country. Source: SHARE wave 6 , release 7.0.0. Author's calculations. All analyses were weighted

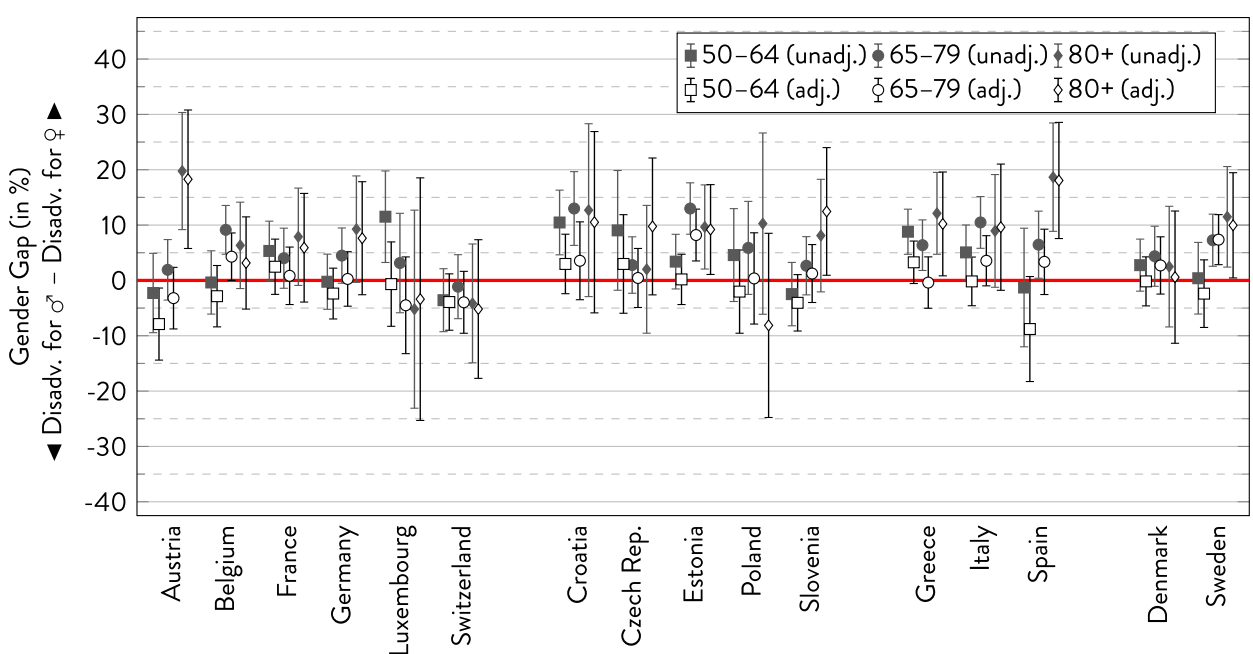


Fig. 5 Gender gap in the presence of pain across age groups by country. Source: SHARE wave 6 , release 7.0.0. Author's calculations. All analyses were weighted

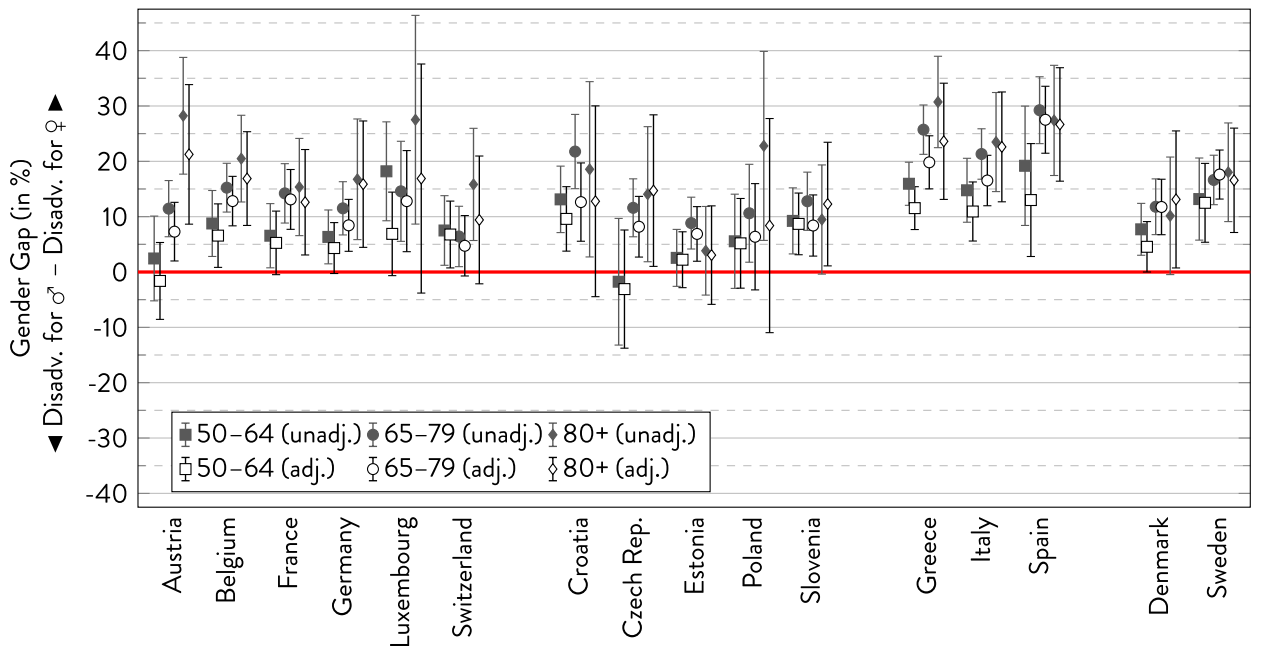

\section{Presence of pain}

Across most countries and age groups, there were strong and statistically significant gender gaps in the presence of pain at the expense of women (Fig. 5). In countries with consistent age trends, gender gaps tended to increase with age with the largest gaps in the oldest age group in Austria, Luxembourg, Poland, Greece, and Spain. While there were some inconsistent age trends, a reversing gender gap at older ages to the disadvantage of men did not occur. The only apparent regional similarity was that the gender gap in pain was most pronounced in Southern European countries where it also more often tended to increase with age. Like before, if there were notable differences, adjusting for covariates typically reduced the gender gap in pain, albeit not statistically significantly.

\section{Heart attacks}

As displayed in Fig. 6, the prevalence of heart attacks was generally higher in men than in women in almost all countries-at least in the younger age groups. However, the gender gap was overall smaller than for the other indicators. Especially in the youngest age group, the gender gap was rather small, whereas differences were increasing in the older age groups in some countries at the expense of men (France, Switzerland, Estonia, Poland, Greece, and Italy). In contrast, the gender gap was narrowing in Slovenia, Spain, and Denmark. In all other countries, age trends were either inconsistent or non-existent. Regarding countries' geographical location, the gender gap in heart attack prevalence was especially small across all age groups in some countries of Eastern Europe and more pronounced in Southern Europe, especially in Greece. Adjusting for covariates did not affect the gender gap strongly with the notable exception of changing the gap to the disadvantage of women in the oldest age
Fig. 6 Gender gap in heart attack across age groups by country. Source: SHARE wave 6 , release 7.0.0. Author's calculations. All analyses were weighted

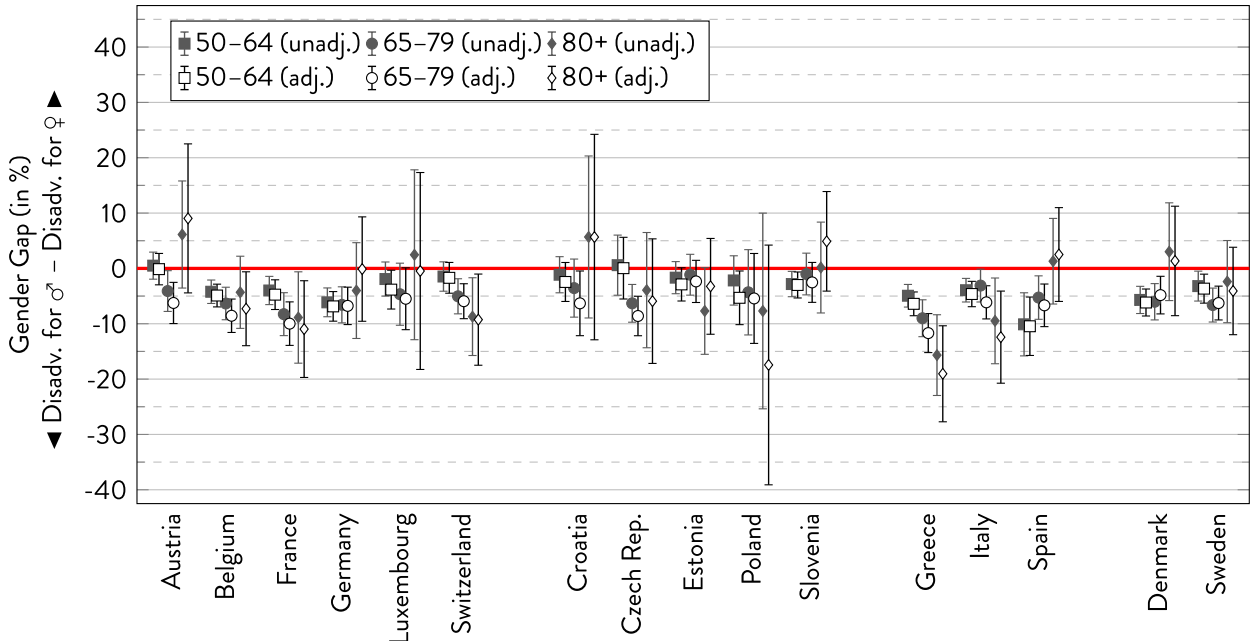


Fig. 7 Gender gap in diabetes across age groups by country. Source: SHARE wave 6 , release 7.0.0. Author's calculations. All analyses were weighted

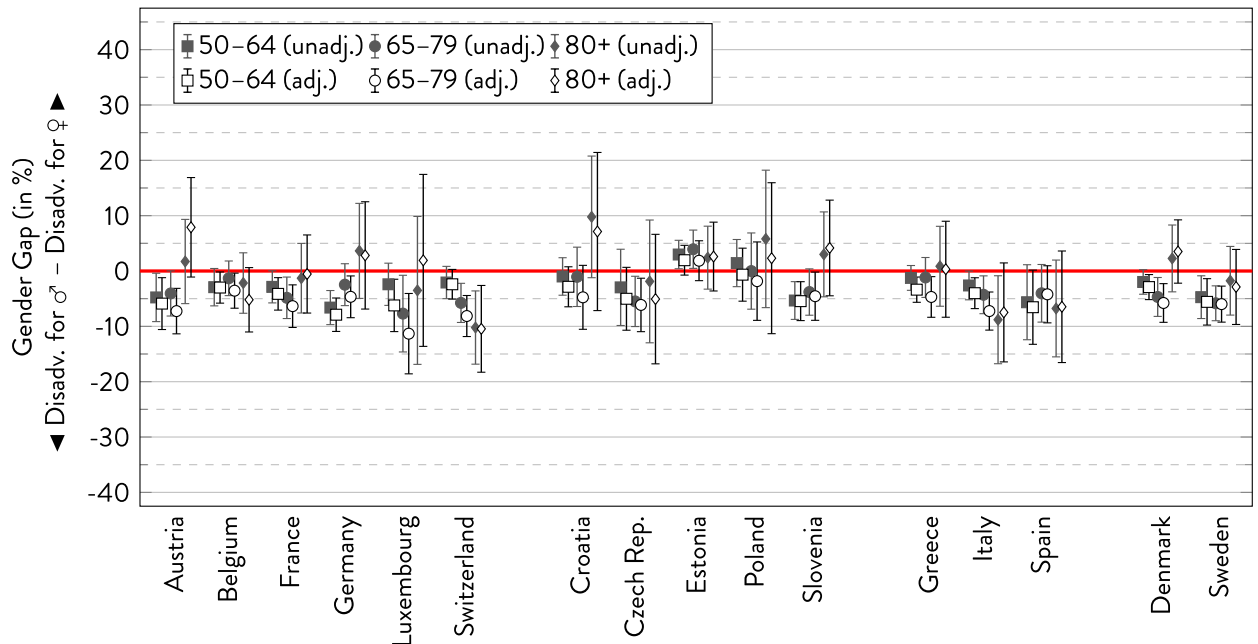

group in Austria and Slovenia and reinforcing the gender gap to men's disadvantage in the oldest old in Poland.

\section{Diabetes}

Looking at the gender gap in diabetes, the prevalence was greater in men than in women in most cases (Fig. 7). Similar to the findings on heart attacks, the gender gap in diabetes was rather small and not statistically significant in most countries. There was a reversing gap to the disadvantage of women in the oldest age group in some countries, whereas the gender gap increased at the expense of men only in Switzerland and Italy. Only minor and inconsistent age differences between age groups were observed in the remaining countries. As for geographical location, a gender gap nominally to the disadvantage of women was observed more often in the Eastern European countries. As with heart attacks, adjusting for socio-demographic variables hardly changed the results in most cases with a slight tendency of increasing the disadvantage for men.

\section{Depression according to EURO-D}

Of all health indicators considered in our analysis, Fig. 8 documents that depression showed the clearest gender health gap across all countries and age groups. There were only few non-significant gender gaps in the younger and in the oldest age group (however, in part due to large confidence intervals). Regarding age trends, there were some countries with a nominal increase to the disadvantage of women, some with a decrease in the gap in favour of women, and also countries with no apparent systematic changes. When looking at regional similarities, the gender gap in depression tended to be highest in Southern Europe across all age groups and relatively small in Northern Europe. As for the other indicators, but more strongly, adjusting for covariates
Fig. 8 Gender gap in depression across age groups by country. Source: SHARE wave 6 , release 7.0.0. Author's calculations. All analyses were weighted

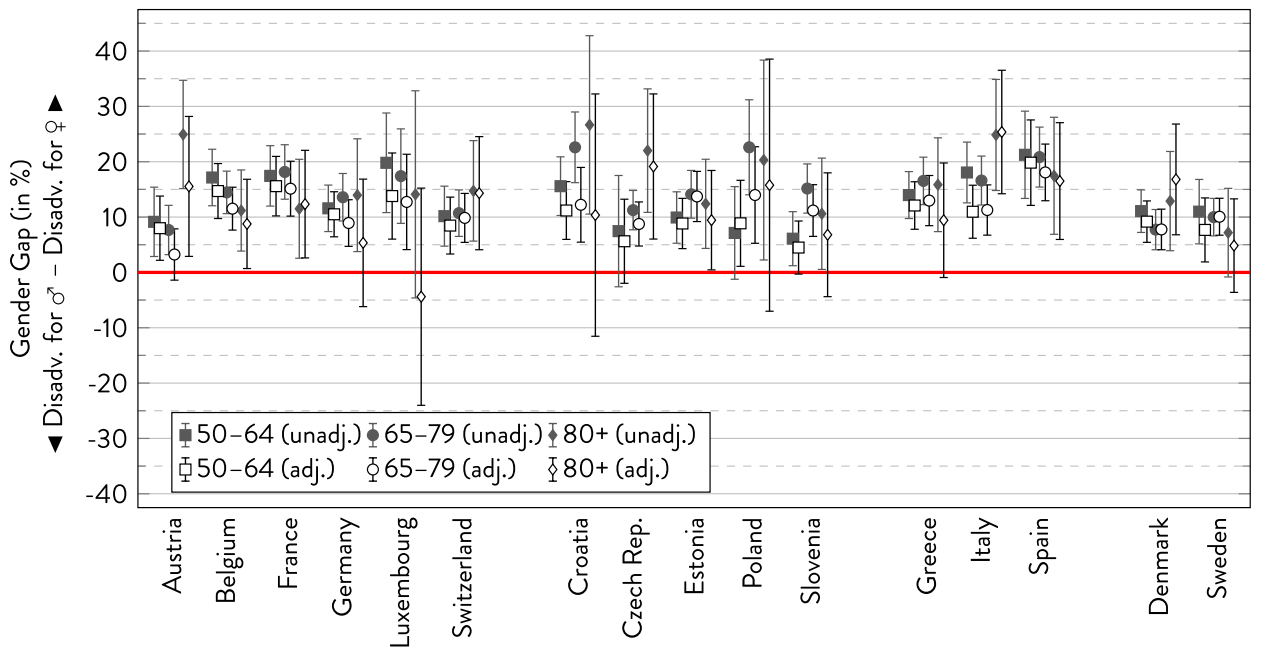


decreased gender gaps, leading to insignificant differences between woman and men especially in the oldest age group.

\section{Discussion}

To the best of our knowledge, our study is the first to examine the gender health gap across different age groups in Europe's ageing societies including a wide range of health indicators. In the pooled SHARE sample, without and with adjustment for covariates, women displayed a worse health status with respect to most of the health indicators with only the prevalences of heart attacks and diabetes being higher in men.

\section{Gender health gap: universal findings across countries and age groups?}

Whereas our analyses support the findings of a range of studies showing a female excess in depression (Acciai and Hardy 2017) and pain (Bartley and Fillingim 2013), the existence of a gender gap cannot be taken for granted for most of the other health indicators: Our results do not universally reflect a female excess in activity limitations and multimorbidity found in many other studies (see the overviews in Leveille et al. 2000 for activity limitations and Violan et al. 2014 for multimorbidity). In a similar vein, the often stated male predominance in heart attacks (Oksuzyan et al. 2018) was not confirmed in all age groups and countries. However, discrepancies in the results might also stem from differences in the operationalisation of health indicators, study populations, and statistical methods.

Furthermore, the gender gap's magnitude was small in many age groups across countries and often statistically not significant, so that there might be no actual gender gap. All in all, we conclude that the gender health gap cannot be regarded as 'given' in Europe's ageing populations. Instead, the direction and the magnitude of health inequalities between women and men strongly depend on the health indicator, age group, and country under study. Even some of the 'taken-for-granted assumptions' (e.g. women rate their health worse than men do; more men suffer from potentially lethal conditions like heart attacks) are not universally reflected by our empirical results.

Further, our results clearly demonstrate the necessity of differentiating between age groups when comparing women's and men's morbidity profiles as the gender gap in SRH, activity limitations, multimorbidity, pain, and depression was mostly increasing with age at the expense of women. In contrast, gender differences in heart attacks were widening to the disadvantage of men in older age groups in some countries. Concerning diabetes, which was more common in men than women in the younger age groups, the gender gap reversed in old age. For chronic health conditions and depression, no clear age trends were identified.

Last but not least, some regional similarities were identified. The gender gap in heart attacks was relatively small in Eastern Europe as compared to other regions. Southern Europe stood out with comparably large gaps to the disadvantage of women for poor SRH, activity limitations, pain, and depression. In Northern Europe, gender differences in multimorbidity, depression, and SRH were rather small as compared to the other regions.

\section{Underlying mechanisms of the gender health gap and implications for future research}

While biological factors such as genetic, anatomical, and endocrine characteristics might explain gender differences in health to some extent, biological explanations cannot explain the variations in the gender health gap between countries that we found in our study. Social explanations of the gender gap in health focus on gender differences in socio-economic status, psychosocial characteristics, and health behaviours. It is likely that the relevance of these explanations depends on the health indicator under study: For example, whereas the gender gap in chronic diseases like diabetes might be largely explained by gender differences in dietary habits and physical activity, these factors are certainly less relevant with regard to the gender gap in depression for which a complex interplay of social and biological factors has been proposed (Kuehner 2017). For generic health indicators like SRH, activity limitations, multimorbidity, and pain, disentangling the underlying mechanisms of the gender health gap promises to be an even greater challenge.

Overall, our results support the relevance of social explanations for the gender health gap as it was typically reduced or even reversed to the advantage of women when controlling for covariates that represented social determinants of health. Since women - at least in older birth cohorts-are typically disadvantaged in terms of resources such as education and income, a reduction in the gender gap by including these covariates fits these explanations. However, as the gender gaps did not fully vanish when controlling for covariates, it seems likely that these explanations are not solely responsible for the health differences between women and men. Yet, acknowledging the influence of social determinants of health, as demonstrated in this paper, provides a starting point for policy makers to reduce gender differences in health. For some health indicators, we observed a greater gender health gap to the disadvantage of women in Southern Europe, while gender inequalities were less pronounced in the Northern European countries. These findings are in line with studies demonstrating that greater gender equality-typically found in the Nordic social democratic welfare 
regimes-has a positive health effect on the health of women (King et al. 2018; Borrell et al. 2014).

Finally, we conclude that gender differences in health in one age group and country are not necessarily generalisable to other age groups and countries so that periodic re-examinations of the gender health gap are mandatory in order to develop and monitor targeted interventions for reducing health inequalities between women and men. Furthermore, our results suggest that gender differences in health should be considered when reforming labour market and healthcare policy in Europe's ageing societies. For example, in the field of policies for extending the working life, there is a tendency to think of the end of working life as gender neutral or following a typical male trajectory (Loretto and Vickerstaff 2015). This falls short as poor health, whose likelihood differs by gender, is the most important barrier to extended working lives, and also the nature of work itself differs by gender (Edge et al. 2017).

\section{Limitations}

There are several limitations of our study. First, our analysis is based on self-reported health measures which bear the risk of bias due to systematic differences in reporting styles of people of different age groups, educational and cultural backgrounds (Jürges 2007). While it is likely that health indicators which are based on a subjective evaluation (e.g. SRH) are influenced by such reporting differences (Lazarevič 2018), this bias might be of less relevance for indicators such as diagnosed diseases. Still, even results on diagnosed diseases might be biased due to differences in the healthcare utilisation of women and men (for diabetes, see Cowie et al. 2006 or a differential chance of survival; for heart attacks, see Sun et al. 2018). Furthermore, our study was limited to the countries included in SHARE, so that regional differences should be interpreted with caution. Further analyses incorporating other or even more countries are desirable. It must also be mentioned that the confidence intervals of the gender gaps were often relatively large due to small sample sizes or a low prevalence of certain health conditions in some age groups. In addition, the study sample consists of people living in private households. As the likelihood of older adults being institutionalised varies across countries with different long-term care options, it must be kept in mind that older adults with poor health remain in their households in some countries, whereas their counterparts in other countries live in institutions. An analysis of the gender health gap in institutionalised individuals, while not possible with the data used here, would be highly desirable.

Finally, yet importantly, differences at the level of the overall population can, as this study has shown with regard to age and country, mask considerable inequalities within the aggregate. A disadvantage of one group in the whole population with respect to a certain health indicator does not necessarily imply that all subgroups of women and men face this health disadvantage (Schofield 2012). Hence, more studies investigating the gender health gap in different population groups (e.g. between different socio-economic groups) are needed to evolve our understanding of the relationship between gender and health.

These shortcomings, however, do not challenge our main conclusion that the relationship between gender and health defies easy summary as even some of the 'taken-for-granted assumptions' were not completely supported in our analysis of the gender health gap in Europe's ageing populations.

Acknowledgements This project has received funding from the European Research Council (ERC) under the European Union's Horizon 2020 research and innovation programme (Grant agreement No. 725187). This paper uses data from SHARE Wave 6 (https ://doi.org/10.6103/share.w6.610); see Börsch-Supan et al. (2013) for methodological details. The SHARE data collection has been primarily funded by the European Commission through FP5 (QLK6CT-2001-00360), FP6 (SHARE-I3: RII-CT-2006-062193, COMPARE: CIT5-CT-2005-028857, SHARELIFE: CIT4-CT-2006-028812) and FP7 (SHARE-PREP: $N^{\circ} 211909$, SHARE-LEAP: $N^{\circ} 227822$, SHARE M4: $N^{\circ}$ 261982). Additional funding from the German Ministry of Education and Research, the Max Planck Society for the Advancement of Science, the US National Institute on Aging (U01_ AG09740-13S2, P01_AG005842, P01_AG08291, P30_AG12815, R21_AG025169, Y1-AG-4553-01, IAG_BSR06-11, OGHA_04-064, HHSN271201300071C) and from various national funding sources is gratefully acknowledged (see www.share-project.org).

\section{Compliance with ethical standards}

Conflict of interest The authors declare that they have no conflict of interest.

Ethical approval Until July 2011, the Survey of Health, Ageing and Retirement in Europe (SHARE) was reviewed and approved by the Ethics Committee of the University of Mannheim. Since then, the Ethics Council of the Max Planck Society for the Advancement of Science (MPG) is responsible for ethical reviews and the approval of the study.

Open Access This article is licensed under a Creative Commons Attribution 4.0 International License, which permits use, sharing, adaptation, distribution and reproduction in any medium or format, as long as you give appropriate credit to the original author(s) and the source, provide a link to the Creative Commons licence, and indicate if changes were made. The images or other third party material in this article are included in the article's Creative Commons licence, unless indicated otherwise in a credit line to the material. If material is not included in the article's Creative Commons licence and your intended use is not permitted by statutory regulation or exceeds the permitted use, you will need to obtain permission directly from the copyright holder. To view a copy of this licence, visit http://creativecommons.org/licenses/by/4.0/. 


\section{Appendix}

Table A1 Sample characteristics by country

\begin{tabular}{|c|c|c|c|c|c|c|c|c|c|c|}
\hline & \multirow[t]{2}{*}{$N$} & \multicolumn{2}{|l|}{ Age } & \multicolumn{3}{|c|}{$\begin{array}{l}\text { Share of age groups (in } \\
\% \text { ) }\end{array}$} & \multicolumn{4}{|c|}{$\begin{array}{l}\text { Share of women by age groups } \\
\text { (in \%) }\end{array}$} \\
\hline & & Mean & SD & $50-64$ & $65-79$ & $80+$ & $50-64$ & $65-79$ & $80+$ & Total \\
\hline Austria & 2835 & 66.31 & 10.13 & 50.40 & 36.87 & 12.73 & 53.09 & 55.13 & 63.88 & 55.21 \\
\hline Belgium & 5147 & 65.14 & 10.68 & 52.26 & 35.23 & 12.52 & 50.33 & 52.69 & 60.99 & 52.49 \\
\hline France & 3505 & 65.40 & 10.94 & 51.58 & 34.89 & 13.53 & 51.01 & 54.91 & 63.71 & 54.09 \\
\hline Germany & 4075 & 66.02 & 10.29 & 49.99 & 37.91 & 12.11 & 51.21 & 53.29 & 64.59 & 53.62 \\
\hline Luxembourg & 1419 & 63.87 & 10.22 & 56.93 & 32.76 & 10.31 & 50.68 & 51.67 & 60.23 & 51.99 \\
\hline Switzerland & 2493 & 65.94 & 10.01 & 51.07 & 36.00 & 12.93 & 51.14 & 53.06 & 59.45 & 52.91 \\
\hline Croatia & 2298 & 65.58 & 9.85 & 51.73 & 37.48 & 10.79 & 52.11 & 55.94 & 63.60 & 54.79 \\
\hline Czech Rep. & 4014 & 64.73 & 9.59 & 51.59 & 39.09 & 9.32 & 52.60 & 54.50 & 67.36 & 54.72 \\
\hline Estonia & 4574 & 66.70 & 10.48 & 46.34 & 39.74 & 13.93 & 56.75 & 64.06 & 73.70 & 62.02 \\
\hline Poland & 1462 & 63.73 & 9.92 & 59.51 & 31.82 & 8.67 & 50.89 & 61.47 & 72.19 & 56.10 \\
\hline Slovenia & 3716 & 65.12 & 10.25 & 53.55 & 35.23 & 11.22 & 50.05 & 55.64 & 69.68 & 54.22 \\
\hline Greece & 4371 & 66.09 & 10.74 & 49.29 & 36.04 & 14.67 & 52.46 & 53.06 & 56.21 & 53.23 \\
\hline Italy & 4454 & 65.69 & 10.61 & 48.04 & 39.20 & 12.76 & 51.92 & 53.56 & 60.96 & 53.72 \\
\hline Spain & 4264 & 65.28 & 10.54 & 53.13 & 34.49 & 12.38 & 50.88 & 54.84 & 60.57 & 53.45 \\
\hline Denmark & 3446 & 65.20 & 10.06 & 50.29 & 39.50 & 10.20 & 51.02 & 51.22 & 63.54 & 52.37 \\
\hline Sweden & 3373 & 67.00 & 10.18 & 44.73 & 41.19 & 14.08 & 49.80 & 51.74 & 61.20 & 52.20 \\
\hline Total & 55,446 & 65.51 & 10.47 & 51.19 & 36.57 & 12.24 & 51.29 & 54.47 & 63.23 & 53.91 \\
\hline
\end{tabular}

Source: SHARE wave 6, release 7.0.0. Authors' calculations. All analyses were weighted

\section{References}

Acciai F, Hardy M (2017) Depression in later life: a closer look at the gender gap. Soc Sci Res 68:163-175

Ahrenfeldt LJ, Möller S, Thinggaard M, Christensen K, Lindahl-Jacobsen R (2019) Sex differences in comorbidity and frailty in Europe. Int J Public Health 64(7):1025-1036

Bardage C, Pluijm SMF, Pedersen NL, Deeg DJH, Jylhä M, Noale M, Blumstein T, Otero A (2005) Self-rated health among older adults. A cross-national comparison. Eur J Ageing 2(2):149-158

Bartley EJ, Fillingim RB (2013) Sex differences in pain. A brief review of clinical and experimental findings. Br J Anaesth 111(1):52-58

Bird CE, Rieker PP (2008) Gender and health: The effects of constrained choices and social policies. Cambridge University Press, Cambridge

Bird CE, Lang ME, Rieker PP (2012) Changing gendered patterns of morbidity and mortality. In: Kuhlmann E, Annandale E (eds) The Palgrave handbook of gender and healthcare, 2nd edn. Palgrave, Basingstoke, pp 145-161

Bonsang E, Skirbekk V, Staudinger UM (2017) As you sow, so shall you reap: gender-role attitudes and late-life cognition. Psychol Sci 28(9):1201-1213

Borrell C, Palencia L, Muntaner C, Urquia M, Malmusi D, O'Campo $P$ (2014) Influence of macrosocial policies on women's health and gender inequalities in health. Epidemiol Rev 36:31-48

Börsch-Supan A, Brandt M, Hunkler C, Kneip T, Korbmacher J, Malter F, Schaan B, Stuck S, Zuber S (2013) Data resource profile: the Survey of Health, Ageing and Retirement in Europe (SHARE). Int J Epidemiol 42(4):992-1001

Brandt M (2013) Intergenerational help and public assistance in Europe: a case of specialization? Eur Soc 15(1):26-56
Breivik H, Collett B, Ventafridda V, Cohen R, Gallacher D (2006) Survey of chronic pain in Europe: prevalence, impact on daily life, and treatment. Eur J Pain 10(4):287-333

Cipollone A, Patacchini E, Vallanti G (2012) Women's labour market performance in Europe: trends and shaping factors. CEPS Special Report 66. Centre for European Policy Studies

Commission European (2015) Demography report. Publications Office of the European Union, Luxemburg

Courtenay WH (2000) Constructions of masculinity and their influence on men's well-being: a theory of gender and health. Soc Sci Med 50:1385-1401

Cowie CC, Rust KF, Byrd-Holt DD, Eberhardt MS, Flegal KM, Engelgau MM, Saydah SH, Williams DE, Geiss LS, Gregg EW (2006) Prevalence of diabetes and impaired fasting glucose in adults in the U.S. population. National Health And Nutrition Examination Survey 1999-2002. Diabetes Care 29(6):1263-1268

Crimmins EM, Kim JK, Sole-Auro A (2010) Gender differences in health: results from SHARE, ELSA and HRS. Eur J Public Health 21(1):81-91

Edge CE, Cooper AM, Coffey M (2017) Barriers and facilitators to extended working lives in Europe: a gender focus. Public Health $\operatorname{Rev} 38: 2$

Haberkern K, Schmid T, Szydlik M (2015) Gender differences in intergenerational care in European welfare states. Ageing Soc 35(2):298-320

Jagger C, Robine JM, van Oyen H, Cambois E (2008) Life expectancy with chronic morbidity. In: European Commission (ed) Major and chronic diseases. Report 2007. Luxembourg, pp 292-304

Jagger C, Gillies C, Cambois E, van Oyen H, Nusselder W, Robine J-M (2010) The global activity limitation index measured function and disability similarly across European countries. J Clin Epidemiol 63(8):892-899 
Jürges H (2007) True health vs response styles: exploring cross-country differences in self-reported health. Health Econ 16(2):163-178

Jylhä M (2009) What is self-rated health and why does it predict mortality? Towards a unified conceptual model. Soc Sci Med 69(3):307-316

King TL, Kavanagh A, Scovelle AJ, Milner A (2018) Associations between gender equality and health: a systematic review. Health Promot Int 35(1):27-41

Kuehner C (2017) Why is depression more common among women than among men? Lancet Psychiatry 4(2):146-158

Lachman ME, Neupert SD, Agrigoroaei D (2011) The relevance of control beliefs for health and ageing. In: Schaie KW, Willis SL (eds) Handbook of the psychology of aging. Elsevier, New York, pp 175-190

Lahelma E, Arber S, Martikainen P, Rahkonen O, Silventoinen K (2001) The myth of gender differences in health: social structural determinants across adult ages in Britain and Finland. Curr Sociol 49(3):31-54

Lazarevič P (2018) Ausgezeichnet, sehr gut, gut, mittelmäßig, schlecht: theoretische Konzepte und empirische Befunde zur Erhebung des allgemeinen Gesundheitszustands bei älteren und alten Menschen. In: Brandt M, Fietz J, Hampel S, Kaschowitz J, Lazarevič P (eds) Methoden der empirischen Alter(n)sforschung. Beltz, Weinheim, pp 16-37

Leveille SG, Resnick HE, Balfour J (2000) Gender differences in disability: evidence and underlying reasons. Aging Clin Exp Res 12:106-112

Loretto W, Vickerstaff S (2015) Gender, age and flexible working in later life. Work Empl Soc 29(2):233-249

Luy M (2003) Causes of male excess mortality: insights from cloistered populations. Popul Dev Rev 29(4):647-676

Macintyre S, Hunt K, Sweeting H (1996) Gender differences in health: are things really as simple as they seem? Soc Sci Med 42(4):617-624

Mahalik JR, Burns SM, Syzdek M (2007) Masculinity and perceived normative health behaviors as predictors of men's health behaviors. Soc Sci Med 64(11):2201-2209

Marengoni A, Angleman S, Melis R, Mangialasche F, Karp A, Garmen A, Meinow B, Fratiglioni L (2011) Aging with multimorbidity. A systematic review of the literature. Ageing Res Rev 10(4):430-439

Munich Center for the Economics of Aging (2018) SHARE release guide 7.0.0. http://www.share-project.org/data-documentation/ release-guides.html. Accessed 12 Feb 2020

Murray CJL, Lopez AD (2013) Measuring the global burden of disease. N Engl J Med 369(5):448-457

Oksuzyan A, Juel K, Vaupel JW, Christensen K (2008) Men: good health and high mortality. Sex differences in health and aging. Aging Clin Exp Res 20(2):91-102

Oksuzyan A, Brønnum-Hansen H, Jeune B (2010) Gender gap in health expectancy. Eur J Ageing 7(4):213-218

Oksuzyan A, Gumà J, Doblhammer G (2018) Sex differences in health and survival. In: Doblhammer G, Gumà J (eds) A demographic perspective on gender, family and health in Europe. Springer, Cham, pp 65-100

Oksuzyan A, Dańko MJ, Caputo J, Jasilionis D, Shkolnikov VM (2019) Is the story about sensitive women and stoical men true? Gender differences in health after adjustment for reporting behavior. Soc Sci Med 228:41-50. https://doi.org/10.1016/j.socsc imed.2019.03.002

Prince MJ, Reischies F, Beekman ATF, Fuhrer R, Jonker C, Kivela S-L, Lawlor BA, Lobo A, Magnusson H, Fichter M, van Oyen H, Roelands M, Skoog I, Turrina C, Copeland JRM (1999) Development of the EURO-D scale - a European Union initiative to compare symptoms of depression in 14 European centres. B J Psych 174:330-338

Read JG, Gorman BG (2011) Gender and health revisited. In: Pescosolido BA, Martin JA, McLeod JD, Rogers A (eds) Handbook of the sociology of health, illness and healing. A blueprint for the 21st century. Springer, New York, pp 411-429

Robine JM, Jagger C (2003) Report to Eurostat on European health status module. Final report of convention Eurostat $n^{\circ} 200135100021$. Euro-REVES, Montpellier

Roy K, Chaudhuri A (2012) Gender differences in healthcare utilization in later life. In: Kuhlmann E, Annandale E (eds) The Palgrave handbook of gender and healthcare, 2nd edn. Palgrave McMillan, Basingstoke, pp 256-272

Scheel-Hincke LL, Möller S, Lindahl-Jacobsen R, Jeune B, Ahrenfeldt LJ (2019) Cross-national comparison of sex differences in ADL and IADL in Europe: findings from SHARE. Eur J Ageing 64(7): 1025

Schmid T, Brandt M, Haberkern K (2012) Gendered support to older parents: do welfare states matter? Eur J Ageing 9(1):39-50

Schmitz A, Brandt M (2019) Gendered patterns of depression and its determinants in older Europeans. Arch Gerontol Geriatr $82: 207-216$

Schofield T (2012) Men's health and well-being. In: Kuhlmann E, Annandale E (eds) The Palgrave handbook of gender and healthcare, 2nd edn. Palgrave, Basingstoke, pp 273-289

Sen G, George A, Östlin P (2002) The case for gender equity in health research. J Health Manag 4(2):99-117

Sun LY, Tu JV, Coutinho T, Turek M, Rubens FD, McDonnell L, Tulloch H, Bader Eddeen A, Mielniczuk LM (2018) Sex differences in outcomes of heart failure in an ambulatory, population-based cohort from 2009 to 2013. CMAJ 28(190):E848-E854

Thoits PA (2011) Mechanisms linking social ties and support to physical and mental health. J Health Soc Behav 52(2):145-161

UNESCO (1997) International standard classification of education 1997. UNESCO, Geneva

van Oyen H, van der Heyden J, Perenboom R, Jagger C (2006) Monitoring population disability: evaluation of a new global activity limitation indicator (GALI). Soz Präventivmed 51(3):153-161

Violan C, Foguet-Boreu Q, Flores-Mateo G, Salisbury C, Blom J, Freitag M, Glynn L, Muth C, Valderas JM (2014) Prevalence, determinants and patterns of multimorbidity in primary care. A systematic review of observational studies. PLoS ONE 9(7):e102149

WHO (2019) Gender, equity and human rights. https://www.who.int/ health-topics/gender. Accessed 14 Feb 2020

Publisher's Note Springer Nature remains neutral with regard to jurisdictional claims in published maps and institutional affiliations. 